\title{
Excessive use of motorized vehicular road transports in megacities such as Delhi and Mumbai (India) and its effects on pollution between the years 2004 and 2011
}

\author{
Jacob John ${ }^{1}$ \\ ${ }^{1}$ Vellore Institute of Technology, School of Computer Science and Engineering, Tiruvalam \\ Road, 632014, Vellore, Tamil Nadu, India \\ jacob.john2016@vitalum.ac.in
}

\begin{abstract}
Effects of the increasing use of motor vehicles are almost unnoticeable in large and congested megacities, urban areas, and metropolitan cities such as Mumbai and Delhi. Furthermore, a significant source of air pollution in several Indian cities is transportation. With the rapid growth in urbanization, industrialization, and modernization in such cities, alongside an increase in pollution, the effects of this urban pollution occur at an enormous scale over the long run. The discrepancy in ambient air quality is exceptionally high in megacities. This deteriorating lifestyle could encourage the government to search for a feasible, plausible, and commonly acceptable (by the public, i.e., citizens) solution for such an issue. This paper recognizes the problem at an early stage. It analyzes the solution over a long-term period by considering Singapore's area licensing scheme and certificate of entitlement (COE) bidding system as a successful platform.
\end{abstract}

Keywords: Air pollution, vehicular pollution, certificate of entitlement

\section{Introduction}

The majority of the people in India are exposed to low-quality air. Air pollution is a grave environmental concern in cities such as Delhi and Bombay. According to [6], transportation was a significant contributor towards deteriorating air quality in Mumbai and Delhi. The transportation sector's contribution to ambient air quality discrepancies is as high as $72 \%$ in Mumbai and $48 \%$ in Delhi.

Pollution is defined as the release of harmful contaminants in the environment. Such pollutants cause bodily harm and uneasiness to living organisms such as human beings and animals. In this paper, the entities of this definition are referred to as,

1. the contaminants - the harmful gases released upon the combustion of petrol and diesel in automobiles

2. the environment - the urban city of Delhi and Bombay

3. bodily harm and uneasiness to living organisms - respiratory diseases and other serious ailments. 
So far, the point source of pollution ${ }^{1}$, in this case, is identified as the land transport vehicle with the primary pollutants ${ }^{2}$ as the products of combustion of petrol and diesel.

Urbanization has a significant impact on the population as well. Urbanization is an important factor in increasing and decreasing a country's birth and death rates, respectively [10]. Therefore, the overall population density of Delhi and Mumbai increases, which makes the impact of these pollutants more significant. In Delhi, the population density has grown from 9,294 persons $/ \mathrm{km}^{2}$ in 2001 [6] to 11,312 persons $/ \mathrm{km}^{2}$ in 2011 [5] which is over a $20 \%$ rise. Furthermore, it also brings a rise in the total number of vehicles on the road, as it is more likely that people own vehicles. This is also a result of the increase in the purchasing power parity due to urbanization. Thereby this increases the concentration of various pollutants in the atmosphere. $66 \%$ and $52 \%$ of the pollutants in Delhi and Mumbai, respectively, of the astonishing total of 3000 metric tons, are released each day solely by motor vehicles [11].

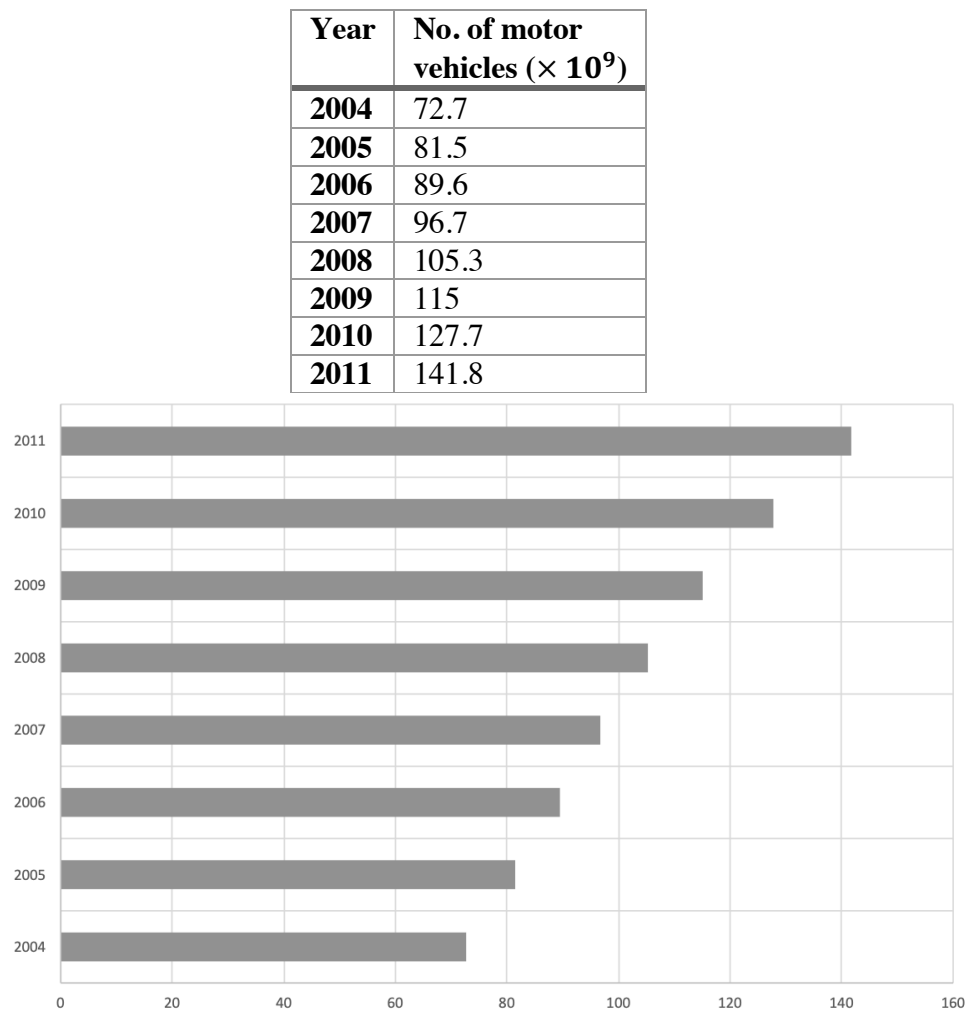

Fig. 1: Number of registered motor vehicles in India [11]

\footnotetext{
${ }^{1}$ Pollution discharged from a single identified pollutant source such as pipe, ditch, ship or factory smoke [7].

${ }^{2}$ Carbon monoxide gas and similar substances produced directly from motor vehicle exhaust are known as primary pollutants [10].
} 
As shown in the data above in figure 1, the number of registered motor vehicles in India has increased significantly. In 2011 , the ratio of cars to people was 0.12 , showing that there is one vehicle for every eight people (roughly two families). Therefore, there is a strong correlation between the number of vehicles and population. The average speed of cars in Indian cities during peak hours is much lesser than the considered optimum speed. Vehicle kilometer, age of the vehicle, and emission rate are some of the defining factors for vehicular emissions [11].

\section{Pollutants and their health effects}

The equation for incomplete combustion as according to [9] is:

$$
\begin{aligned}
& \text { hydrocarbon }+ \text { oxygen } \rightarrow \text { carbon monoxide }+ \text { carbon }+ \text { water } \\
& \text { E.g.: } \\
& \text { methane }+ \text { oxygen } \rightarrow \text { carbon monoxide }+ \text { water } \\
& 2 \mathrm{CH}_{4(\mathrm{~g})}+3 \mathrm{O}_{2(\mathrm{~g})} \rightarrow 2 \mathrm{CO}_{(\mathrm{g})}+4 \mathrm{H}_{2} \mathrm{O}_{(\mathrm{g})}
\end{aligned}
$$

Therefore, as stated above, the increase in motorized transports has caused an increase in the concentration of various primary pollutants. Some primary pollutants are Carbon monoxide (CO) (as shown in the homogenous equation above), Nitrogen oxides $\left(\mathrm{NO}_{\mathrm{x}}\right)$, Sulfur dioxide $\left(\mathrm{SO}_{2}\right)$, Suspended particulate matter (SPM), Respirable particulate matter (RPM), and Hydrocarbons (H). The health effects and symptoms of these pollutants will be discussed later.

Figure 2 illustrates the increase in the total number of vehicles across India over the years. As of 31st March 2011, India has 141.8 million road vehicles that include but are not limited to two-wheelers, four-wheelers, buses, and goods vehicles. India's average consumers' purchasing power parity limits them to purchase a two-wheeler. This phenomenon is further reflected in the data as over $70 \%$ of the total vehicle population across 2004 to 2011 were two-wheelers. Two-wheelers tend to pollute less, given their smaller engine capacity and better fuel economy. However, an increase in the road density (i.e., number of vehicles per square meter) would result in a net increase in air pollution. It should also be noted that the proportion of four-wheelers have also grown over the years from $13 \%$ to $13.6 \%$. Finally, there has been a slight decline in the proportion of goods vehicles. However, the number of goods vehicles has increased from 3.78 million to 7.09 million, rising $88 \%$ in the capacity. 


\begin{tabular}{|c|c|c|c|c|c|c|}
\hline \multirow[t]{2}{*}{$\begin{array}{c}\text { As of } 31^{\text {st }} \\
\text { March }\end{array}$} & $2 W$ & $4 W$ & Buses & $\begin{array}{c}\text { Good } \\
\text { Vehicles }\end{array}$ & $\begin{array}{c}\text { Other } \\
\text { Vehicles }\end{array}$ & \multirow[t]{2}{*}{$\begin{array}{l}\text { Total (in } \\
\text { millions) }\end{array}$} \\
\hline & \multicolumn{5}{|c|}{ As $\%$ of total vehicle population } & \\
\hline 2004 & 71.4 & 13 & 1.1 & 5.2 & 9.4 & 72.7 \\
\hline 2005 & 72.1 & 12.7 & 1.1 & 4.9 & 9.1 & 81.5 \\
\hline 2006 & 72.2 & 12.9 & 1.1 & 4.9 & 8.8 & 89.6 \\
\hline 2007 & 71.5 & 13.1 & 1.4 & 5.3 & 8.7 & 96.7 \\
\hline 2008 & 71.5 & 13.2 & 1.4 & 5.3 & 8.6 & 105.4 \\
\hline 2009 & 71.7 & 13.3 & 1.3 & 5.3 & 8.4 & 115.0 \\
\hline 2010 & 71.7 & 13.5 & 1.2 & 5.0 & 8.6 & 127.7 \\
\hline 2011 & 71.8 & 13.6 & 1.1 & 5.0 & 8.5 & 141.8 \\
\hline
\end{tabular}

$-2 \mathrm{~W}$

$-4 \mathrm{~W}$

- Buses

- Good vehicles

Other vehicles

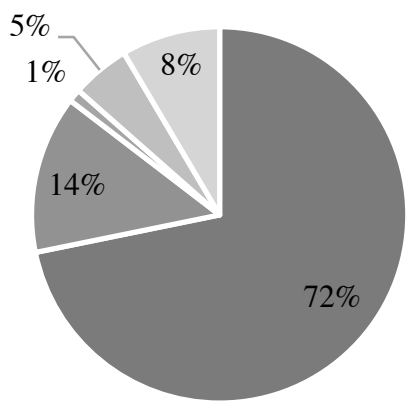

Fig. 2: Composition of vehicles population (\% of total) [11]

\begin{tabular}{|l|c|c|c|c|c|c|}
\hline Categories & $\mathbf{C O}_{\mathbf{2}}$ & $\mathbf{C O}$ & $\mathbf{N O}_{\mathbf{x}}$ & $\mathbf{S O}_{\mathbf{2}}$ & $\mathbf{P M}$ & $\mathbf{H C}$ \\
\hline Bus & 28748.16 & 207.26 & 679.73 & 79.24 & 31.36 & 51.72 \\
\hline Omni Buses & 8508.42 & 60.94 & 200.53 & 23.45 & 9.28 & 15.11 \\
\hline 2-wheeler & 8701.08 & 719.64 & 62.15 & 4.25 & 16.36 & 464.49 \\
\hline LMV (passenger) & 4378.10 & 370.29 & 92.93 & 2.11 & 14.52 & 10.16 \\
\hline LMV (Goods) & 4465.58 & 442.04 & 110.94 & 123.02 & 17.33 & 12.13 \\
\hline Cars and Jeep & 23901.22 & 212.30 & 22.14 & 5.67 & 3.22 & 38.01 \\
\hline Taxi & 2367.08 & 10.23 & 5.68 & 117.05 & 0.80 & 1.48 \\
\hline Others & 5705.22 & 57.41 & 64.54 & 32.19 & 3.98 & 8.96 \\
\hline
\end{tabular}

Fig. 3: Emissions from different vehicles in India [11]

As shown in figure 3, most pollutants identified earlier are emitted from buses and light motor vehicles (LMV), with a majority of the emitted pollutant being $\mathrm{CO}_{2}$. Furthermore, a significant number of the cars are $2 \mathrm{~W}$ or $4 \mathrm{~W}$, which consists of over $85 \%$ of all the vehicles. Albeit buses are a smaller proportion of road vehicles than twowheelers, they contribute to almost twice the particulate matter. 
$90 \%$ of the total vehicles in Delhi consist of two-wheelers and four-wheelers [6]. For simplicity purposes, I can assume this model applies to the two megacities opted for this analysis - Delhi, and Mumbai.

On the other hand, besides carbon dioxide, several other harmful air toxins are released into the atmosphere. Their impact on health is listed below:

Carbon monoxide (CO) - Inhaling carbon monoxide could cause dizziness, headache, vomiting, reduced productivity, and/or nausea. By affecting the cardiovascular and nervous system, it impairs physical coordination, vision, and judgment. Furthermore, if the CO levels are too high, it could lead to loss of consciousness or, in extreme cases, death.

Nitrogen oxide $\left(\mathbf{N O}_{\mathbf{x}}\right)$ - Short-term $\mathrm{NO}_{2}$ exposures are said to be linked with adverse respiratory effects such as airway inflammation with people in good health and increased respiratory symptoms for people with asthma.

Sulfur dioxide $\left(\mathbf{S O}_{2}\right)$ - Affects lung functions adversely and causes breathing difficulty, corneal haze, and airway inflammation. It is also associated with chronic bronchitis, asthma, and mortality increase in the elderly and infants.

Suspended particulate matter and Respirable particulate matter (SPM and RPM) - Fine particulate matter itself are toxic. At times, it carries traces of poisonous substances. In both cases, it could harm the immune system or even alter it. Long term disorders are caused when fine particles penetrate deep into the respiratory system and irritate the lung tissue [11].

Hydrocarbons (HC) - Research says HCs can cause cancer. 


\section{Reasons for increasing vehicular pollution}

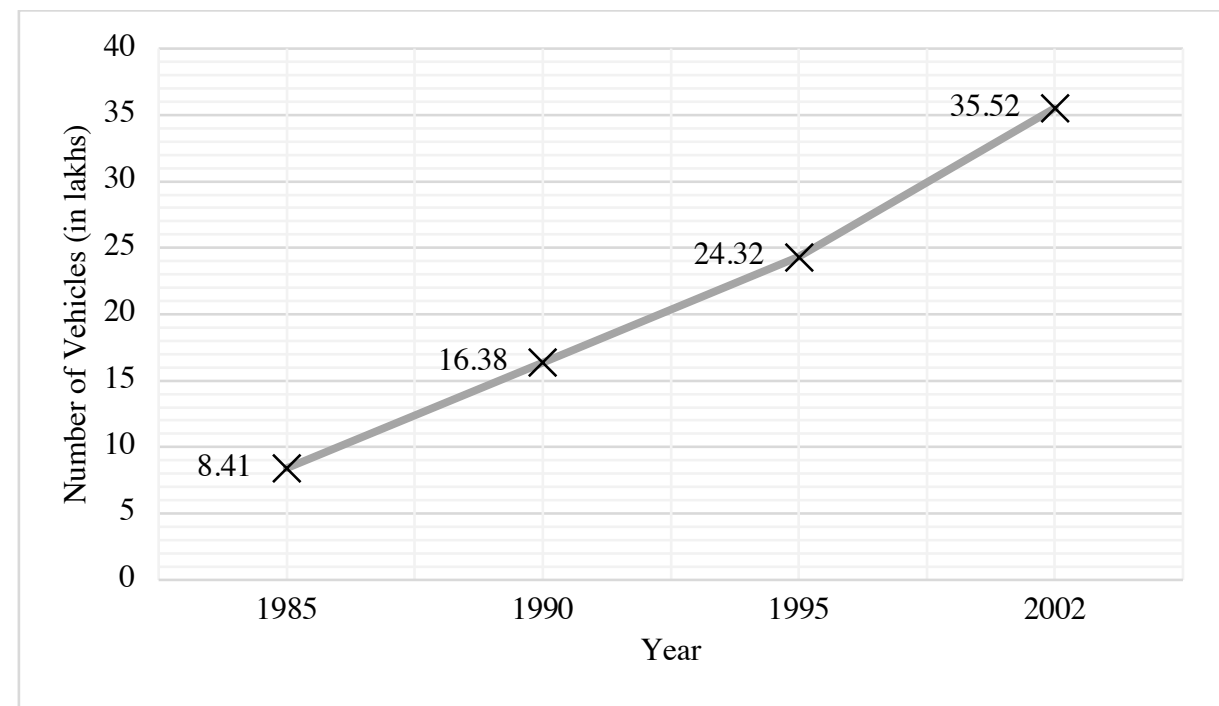

Fig. 4: Annual Growth of the number of registered vehicles in Delhi: 1985-2002 [6]

As shown in figure 4 above, the number of vehicles increased 4.2 times from 1985 to 2002, along with the annual growth rate [6]. Therefore, there exists a positive correlation between the vehicle density in Delhi and air pollution. This is primarily due to two-wheelers and cars. As can be seen in figure 5, there is a dominance in the percentage composition of two-wheelers and cars from 1985 to 2002 in Delhi.

\begin{tabular}{|c|c|c|c|c|c|}
\hline Year & $\mathbf{2 W}$ & $\mathbf{3 W}$ & Cars/Cabs & Buses & $\begin{array}{c}\text { Goods } \\
\text { Vehicles }\end{array}$ \\
\hline $\mathbf{1 9 8 5}$ & 68.8 & 3.6 & 19.8 & 1.6 & 6.2 \\
\hline $\mathbf{1 9 9 0}$ & 68.0 & 3.6 & 21.7 & 1.1 & 5.7 \\
\hline $\mathbf{1 9 9 0}$ & 66.5 & 3.1 & 24.2 & 1.1 & 5.1 \\
\hline $\mathbf{2 0 0 2}$ & 63.8 & 2.4 & 27.9 & 1.3 & 4.6 \\
\hline
\end{tabular}

Fig. 5: The percentage share of different types of vehicles in Delhi (1985-2002) [6]

This also shows that the prevalence of privately owned cars over public transportation could also be another factor affecting increasing vehicular pollution, as supported by figures $2,3,4$, and 5 . 
Another factor is the age of the car. Older cars tend to be less environmentally friendly and leave a more significant carbon footprint ${ }^{3}$. The reason newer cars tend to be more environmentally friendly in the long run is that it includes the environmental cost of manufacturing and how many miles per gallon a car gets [8]. Though building a car is an energy and resource-intensive process, fuel efficiency turns out to be a more important factor over the long run. Studies reveal that in a car's lifetime, $75 \%$ of carbon emissions stem not from its production itself but from the amount of fuel it burns [8].

Other factors include a flawed public transport system, which causes higher idling emissions and traffic congestion. Furthermore, the absence of adequate land use, planning and development of urban and rural areas, and improper traffic management system and road conditions cause more vehicle use as roads are relatively long, increasing fuel consumption [6].

\section{Singapore's traffic model as a solution}

Two of Singapore's successful schemes include the area licensing scheme and the certificate of entitlement scheme. Traffic in the city in Singapore tends to move better than in most Asian cities. Singapore is one of the few Asian countries that has successfully implemented land transport management [12]. With the increasing amount of traffic every year, many roads would be too narrow to accommodate overwhelming demand; there has been a rapid increase in the population of cars over the years (growing from 142,674 in 1974 to 303,864 in 1993). The number of cars to households has increased quadruple times, i.e., at a ratio of 1:4, 1 being the number of households, and 4 the number of cars per household (i.e., 26 per 100 households) in 1980 to 1:3 (i.e., 31 per 100 households) in 1990 [12].

The Singapore government laid out the following as a means to establish new land transport policies:

- Managing and restraining the number of privately owned cars and road usage demand to alleviate traffic congestion.

- Improve road networks (e.g., capacity maximization ${ }^{4}$ ) and integrate land use and a traffic management system to minimize the need to travel, thus reducing congestion during peak hours.

- Making public transportation systems competitive to encourage the development of mass rail transits (MRT), light rail transits (LRT), and bus services.

The goals and objectives are likely to overcome the problems identified in the previous section. This is because, being a small country with an increasing demand for road transportation, Singapore was facing the same issues in the 20th century as Delhi and Bombay have been facing for the past decade.

\footnotetext{
${ }^{3}$ The total amount of greenhouse gases usually expressed in equivalent tons of carbon dioxide $(\mathrm{CO} 2)$ produced, to directly and indirectly support human activities (in this case, vehicular transports) [2]

${ }^{4}$ In this case, increase the number of vehicles on the road to the greatest amount or degree.
} 
The Singapore government also laid out four key strategies. The first strategy is to try to integrate urban development with transport planning successfully. This will be carried out by closely relating the other measures for promoting desired patterns for land use to the expansion of urban transport facilities [12]. For example, having a higher concentration of buildings around mass rapid transit stations and bus stops can ensure good accessibility for commuters and reduce the distances from homes to stations. The second is a road-building program. So far, 11 percent of the country is now taken up by roads compared to 13 percent for housing. The road lengths have grown from $1761 \mathrm{~km}$ in 1965 (the year of India's independence) to $2173 \mathrm{~km}$ in 1975 , and from $2645 \mathrm{~km}$ in 1985 to $2989 \mathrm{~km}$ in 1993 [12].

These measures are likely to effectively reduce traffic congestion and pollution in Delhi only if the demand for vehicles and roads remains constant over the years. As an effect, the Area licensing scheme of 1975 could be a plausible solution for reducing traffic congestion during peak hours as implemented by Singapore for the city center of the small country.

The scheme was based on a 'cordon' 5 pricing system, where the 'cordoned' area was referred to as the "restricted zone". To enter, cars and taxis had to have a special area license on their windscreen to gain entry in this restricted zone. There had been times when carpooling (of at least four persons) by taxis and cars was encouraged and allowed from these areas. This was later stopped in 1989 due to its potential to show an increased amount of congestion. Lastly, keeping with the changing economy and traffic conditions, details of the scheme's operation (e.g., the hours, mode of operation, and charges) have also been adjusted as that primarily resulted in a change in the restricted zone over time [12].

The COE system or the quota scheme is the other one of the two ideas that could be used in Delhi or Bombay. First, obtaining a vehicle registration is made not an easy task. If one wishes to obtain new registration for a vehicle, one would compulsorily need to get a Certificate of Entitlement (COE) in the appropriate vehicle category. This certificate legally entails and represents a right to vehicle ownership and use of the limited road space for ten years. However, at the end of the 10-year COE period, vehicle owners may choose to deregister their vehicle or to revalidate their COEs for a period of another 5 or 10 years by paying the Prevailing Quota Premium [1]. Thus, this also leaves a reduced carbon footprint due to older cares, as discussed earlier.

The COE is split into seven different categories based on engine capacity and intended vehicle usage:

- cars less than $1000 \mathrm{cc}$ (small cars),

- cars 1001-1600cc (medium cars),

- cars 1601-2000cc (big cars),

- cars more than 2000cc (luxury cars),

- "open" category,

- goods vehicles/buses, and

- motorcycles.

${ }^{5}$ Usually surround or blockade an area of land or water with or without a cordon, a verb usually followed by the word off [3] 
Other than vehicles like scheduled buses, school buses, and emergency vehicles such as ambulance and fire engines, the scheme applies to all forms of vehicular locomotives. One must first bid for a COE in a public tender if they intend to register a vehicle. Like most government biddings, the COE premium in each tender is determined by the amount of the lowest successful bid, and all successful bidders pay the same premium [12]. Thus, making the process exclusive.

\section{Evaluation of two schemes}

\begin{tabular}{|l|l|l|l|l|}
\hline \multicolumn{1}{|c|}{ Time (hours) } & \multicolumn{4}{|c|}{ Traffic } \\
\hline & \multicolumn{1}{|c|}{ March 1975 } & March 1976 & \multicolumn{1}{c|}{ May 1979 } & May 1983 \\
\hline Cars & & & & \\
\hline $07: 00-07: 30$ & 5384 & 5675 & 5723 & 6413 \\
\hline $07: 30-10: 15$ & 42790 & 10754 & 13181 & 15473 \\
\hline $10: 15-10: 45$ & - & 6459 & 5527 & 7069 \\
\hline & & & & \\
\hline All vehicles & & & & \\
\hline $07: 00-07: 30$ & 9800 & 10322 & 10596 & 11280 \\
\hline $07: 30-10: 15$ & 70014 & 35787 & 49606 & 57035 \\
\hline $10: 15-10: 45$ & - & 13441 & 15179 & 16490 \\
\hline
\end{tabular}

Fig. 6: Table showing the effects of the area licensing scheme and the COE quota scheme [12]

\begin{tabular}{|l|c|c|c|}
\hline City & $\begin{array}{c}\text { Estimated average } \\
\text { travel speed during } \\
\text { peak times } \mathbf{( k m} / \mathbf{h})\end{array}$ & $\begin{array}{c}\text { Resident population } \\
(\mathbf{1 0 0 0 s})\end{array}$ & $\begin{array}{c}\text { Length of the urban } \\
\text { road network (km) }\end{array}$ \\
\hline Bangkok & 8 & 6612 & 2800 \\
\hline Manila & 10 & 8475 & 1938 \\
\hline Hong Kong & 22 & 5851 & 1559 \\
\hline Singapore & 30 & 2763 & 2924 \\
\hline
\end{tabular}

Fig. 7: Travel speeds in selected Asian countries [12]

The area licensing scheme offers a lot of advantages. Along with being simple to implement and enforce, from a fund saving point of view, it has low capital investment costs and physical requirements. It also has low operating prices. The monthly active fee is approximately $\$ \$ 300,000$. The aim of alleviating traffic congestion has been successful as the scheme has effectively improved traffic conditions within the CBD during peak hours [12]. According to Figure 7, the average estimated speed during peak times is higher than the major (in terms of traffic as of 1998) Asian cities. However, this is justifiable by the other three cities' higher population density and the difference in the 'peak times' in the other towns. On the other hand, Singapore's road network or higher "length of the urban road network" could also explain that the average speed is higher as cars have more space to move. 


\section{Conclusion}

To conclude, Singapore's area licensing scheme and COE system reduce both traffic and congestion and hence, reduce air pollution in Delhi and Bombay. This is because the majority of the air pollution is caused due to vehicles. Additionally, it could reduce the noise pollution in major cities due to the engines' honking and roars.

\section{References}

1. "CERTIFICATE OF ENTITLEMENT (COE)." Lta.gov.sg. Land Transport Authority (Singapore), 25th July 2016. Web. 30th July 2016.

2. Cleveland, Cutler J., and Christopher Morris. Dictionary of Energy. 2nd ed. N.p.: Elsevier, 2015. Print.

3. "Define Cordon." Dictionary.com. Dictionary.com, n.d. Web. 3rd August 2016.

4. "Define Maximization." Dictionary.com. Dictionary.com, n.d. Web. 3rd August 2016.

5. "Delhi Population Census Data 2011." Census2011. Census Population 2015, 2011. Web. 31st July 2016.

6. Goyal, S. K., S. V. Ghatge, P. Nema, and S. M. Tamhane. Understanding Urban Vehicular Pollution Problem Vis-a-vis Ambient Air Quality--case Study of a Megacity (Delhi, India). Publication no. 16741810. PubMed.gov, 2nd June 2006. Web. 30th July 2016.

7. Hill, M.S. 1997. Understanding Environmental Pollution. Cambridge, UK: Cambridge University Press. 316 pp.

8. Ingram, Antony. "Which Is Greener: Old Car or New Car?" The Christian Science Monitor. The Christian Science Monitor, 4th August 2014. Web. 2nd August 2016.

9. "Properties of Alkanes (General)." BBC Bitesize. BBC, n.d. Web. 31st July 2016.

10. Roopan, S. Mohana, Dr., and G. Madhumitha, Dr. Environmental Science for Engineers. 1st ed. Chennai: Sai, 2016. Print.

11. Shrivastava, R. K., Neeta Saxena, and Geeta Gautam. Air Pollution Due To Road Transportation In India: A Review On Assessment And Reduction Strategies. Rep. 1st ed. Vol. 8. N.p.: Journal of Environmental Research And Development, 2013. Print. JulySeptember 2013.

12. Yuan, Lim Lan. A Case Study on Urban Transportation Development and Management in Singapore. Rep. National University of Singapore, n.d. Web. 3rd August 2016. 